asthma, can improve BHR when administered chronically to patients with mild asthma. ${ }^{19}$ This research has many parallels with the use of $\beta$-blockers in the treatment of patients with heart failure where this class of drug was once contraindicated as acute dosing produced adverse effects in such patients. ${ }^{20}$ It was then subsequently recognised that chronic dosing with $\beta$-blockers was beneficial in patients with heart failure, and the use of this drug class is now considered a central part of standard treatment guidelines. So-called "paradoxical pharmacology", where there may be differential effects of acute versus chronic dosing of a given class of drug, would seem to be a very important issue when considering the use of drugs that recognize the $\beta_{2}$ receptor.

Furthermore, given that it has been recently suggested that some $\beta$-blockers act as inverse agonists at the $\beta_{2}$ receptor and activate novel signalling pathways that are required for the full asthma phenotype in mice, ${ }^{22}$ it would seem time to challenge the dogma that activation of $\beta_{2}$ receptors chronically is a good thing. If nothing else, the study by Virchow and colleagues provides further support for why monotherapy with $\beta_{2}$ receptor agonists has no role in the treatment of patients with asthma.

Competing interests: $\mathrm{CP}$ is a co-founder of Verona Pharma which has an interest in developing novel drugs for treating respiratory diseases.
Provenance and peer review: Commissioned; not externally peer reviewed.

Thorax 2009;64:738-739. doi:10.1136/thx.2009.113506

\section{REFERENCES}

1. Page CP, Spina D. Beta2-agonists and bronchial hyperresponsiveness. Clin Rev Allergy Immunol 2006; 31:143-62

2. Cockcroft DW, McParland CP, Britto, et al. Regular inhaled salbutamol and airway responsiveness to allergen. Lancet 1993;342:833-37.

3. Gauvreau GM, Jordana M, Watson RM, et al. Effect of regular inhaled albuterol on allergen-induced late responses and sputum eosinophils in asthmatic subjects. Am J Crit Care Med 1997;156:1738-45.

4. Cheung D, Timmers MC, Zwinderman AH, et al. Long term effects of a long acting beta 2 adrenoceptor agonist, salmeterol, on airway hyperresponsiveness in patients with mild asthma. $N$ Engl J Med 1992:327:1198-203.

5. O'Connor BJ, Aikman SL, Barnes PJ. Tolerance to the non-bronchodilator effects of inhaled beta 2 agonists in asthma. N Engl J Med 1992;327:1204-8.

6. Nelson HS, Weiss ST, Bleeker ER, et al The salmeterol multicentre asthma research trial: a comparison of usual pharmacotherapy for asthma or usual pharmacotherapy plus salmeterol. Chest 2006;129:15-26.

7. Sears MR, Ottosson A, Radner F, et al. Long acting beta agonists: a review of formoterol safety data from asthma clinical trials. Eur Resp J 2009;33:21-32.

8. Lommatzsch $\mathbf{M}$, Lindner $Y$, Edner $A$, et al. Adverse effects of salmeterol in asthma: a neuronal perspective. Thorax 2009;64:763-9.

9. Virchow JC, Julius $\mathrm{P}$, Lommatzsch $\mathrm{M}$, et al. Neurotrophins are increased in bronchoalveolar lavage fluid after segmental allergen provocation. Am J Respir Crit Care Med 1998;158:2002-5.

10. Lommatzsch M, Schloetcke K, Klotz J, et al. Brainderived neurotrophic factor in platelets and airflow limitation in asthma. Am J Respir Crit Care Med 2005;171:115-20.
11. Braun A, Lommatzsch M, Neuhaus-Steinmetz $\mathrm{U}$, et al. Brain-derived neurotrophic factor (BDNF) contributes to neuronal dysfunction in a model of allergic airway inflammation. $\mathrm{Br} \mathrm{J}$ Pharmacol 2004;141:431-40.

12. Noga 0, Hanf G, Schaper C, et al. The influence of inhalative corticosteroids on circulating nerve growth factor, brain-derived neurotrophic factor and neurotrophin-3 in allergic asthmatics. Cli Exp Allergy 2001;31:1906-12.

13. Spina D, Page CP. Asthma-a need for a rethink? Trends Pharmacol Sci 2002;23:311-5.

14. Keir S, Page C, Spina D. Bronchial hyperresponsiveness induced by chronic treatment with albuterol: role of sensory nerves. J Allergy Clin Immunol 2006:118:551-9.

15. Coyle AJ, Page CP, Atkinson L, et al. The requirement of platelets for allergen-induced late asthmatic airways obstruction. Am Rev Respir Dis 1990;142:587-93.

16. Pitchford SC, Riffo-Vasquez $Y$, Sousa A, et al. Platelets are necessary for airway wall remodeling in a murine model of chronic allergic inflammation. Blood 2004;103:639-47.

17. Drazen JM, O'Byrne PM. Risks of long-acting betaagonists in achieving asthma control. N Engl J Med 2009;360:1671-2.

18. Page CP. One explanation of the asthma paradox: inhibition of natural anti inflammatory mechanisms by beta 2-agonists. Lancet 1991;337:717-20.

19. Hanania NA, Singh S, El-Wali R, et al. The safety and effects of the beta blocker, nadolol, in mild asthma: an open label pilot study. Pulm Pharmacol Ther 2008;21:134-41

20. Bond R, Spina D, Parra S, et al. Getting to the heart of asthma: can beta blockers be useful to treat asthma? Pharmacol Ther 2007;115:360-74.

21. Bond RA. Is paradoxical pharmacology a strategy worth pursuing? Trends Pharmacol Sci 2001;22:273-6.

22. Nguyen LP, Lin R, Parra S, et al. Beta2-adrenoceptor signaling is required for the development of an asthma phenotype in a murine model. Proc Natl Acad Sci USA 2009;106:2435-40.

\title{
Mechanisms of adverse effects of $\beta$-agonists in asthma
}

\section{Sebastian L Johnston, Michael R Edwards}

Short-acting $\beta$-agonist (SABA) drugs have been mainstays of asthma therapy for many decades and are recommended treatment at all levels of asthma severity, as they provide prompt relief of asthma symptoms through smooth muscle relaxation and, thereby, bronchodilatation. At all levels of asthma severity more severe than mild intermittent, SABAs are recommended to be taken as required for relief

Department of Respiratory Medicine, National Heart and Lung Institute, MRC \& Asthma UK Centre in Allergic Mechanisms of Asthma, Imperial College London, London, UK

Correspondence to: Professor Sebastian L Johnston, Department of Respiratory Medicine, National Heart and Lung Institute, Imperial College London, Norfolk Place, London W2 1PG, UK; s.johnston@imperial.ac.uk of symptoms in conjunction with inhaled corticosteroids (ICSs) taken as regular maintenance treatment. However, in mild asthma SABAs are recommended as monotherapy without concomitant ICS therapy, and in both mild and more severe asthma, greatly increased SABA use at times of asthma exacerbation is almost universal. Here we discuss the safety of inhaled $\beta$-agonist monotherapy in asthma and argue against the continued use of $\beta$ agonist monotherapy (both short and long acting) in the absence of concomitant ICS therapy in a combination inhaler.

Several epidemiological studies link overuse of SABA therapies at times of asthma exacerbation with increased risk of hospitalisation or mortality. ${ }^{12}$ The mechanisms underlying this increased risk have not been clearly determined, but are most likely to involve complex mechanisms including delays in seeking medical care, potential cardiac (tachycardia) and metabolic (hypokalaemia) adverse effects as well as possible effects on underlying asthma severity. Although fenoterol, the SABA linked with the epidemic of asthma mortality in the early 1980s in New Zealand $^{3}$ and some other countries, ${ }^{4}$ has greater cardiac effects than other SABAs, the reduction in hospitalisations due to asthma exacerbations (along with a reduction in asthma mortality) following the withdrawal of high dose fenoterol in New Zealand in 1990 suggested that the reduction in asthma mortality was not wholly due to reduction in cardiac/ metabolic side effects, but probably also due to an effect on disease severity (because if the reduction in mortality were due to reduction in cardiac side effects, the rate of hospitalisations due to asthma exacerbations should have remained unchanged). ${ }^{5}$ 
The long-acting $\beta$-agonists (LABAs) were introduced as asthma treatments in the 1990s, and their use was shown to result in improved lung function and quality of life. Concerns about possible risks associated with LABA treatment were raised very soon after their introduction-these centred around the potential of regular LABAs to reduce bronchodilator sensitivity to $\beta$-agonists, to induce tolerance to $\beta$-agonists, the risk that the reduction in symptoms achieved with LABAs might reduce awareness of asthma activity and therefore lead to a reduction in usage of ICS therapy or reduced awareness of worsening of asthma control (masking) ${ }^{6}$ and finally that if SABAs do have potential to increase disease severity, LABAs might possess this property as well. These concerns were increased by the Salmeterol Multicenter Asthma Research Trial (SMART) - this placebocontrolled study on the safety of the LABA salmeterol in adults with unstable asthma showed a statistically significant, fourfold increase in asthma-related deaths with salmeterol. ${ }^{7}$ It was not possible to determine if the risk extended to patients receiving concomitant ICS treatment, nor therefore whether the risk was restricted to the use of salmeterol as monotherapy. In view of these concerns, the Food and Drug Administration (FDA) required black-box warnings on the product labels of both salmeterol and formoterol and recommended that further research was needed into the nature and magnitude of risk with LABA treatment.

These data led to three important questions relating to $\beta$-agonist treatment in asthma. What is the evidence that SABAs or LABAs may increase the underlying severity of asthma, what mechanisms might be involved and what is the evidence that ICSs may protect against an increase in severity consequent upon SABA or LABA treatment?

Regarding the first two questions, regular use of SABA was shown some time ago significantly to increase peak flow variability and bronchial hyperresponsiveness when compared with asrequired use during the run-in period of the study, ${ }^{8}$ to increase eosinophilic and mast cell responses to allergen challenge, to induce non-specific bronchial hyperreactivity ${ }^{5}$ and to increase sputum eosinophil counts'; however, the mechanisms underlying these potential adverse effects are not known.

A report in this issue of Thorax sheds some new light on a potential mechanism that may be involved in adverse effects of $\beta$-agonists (see page 763). Lommatzsch et al show that 14 days monotherapy with salmeterol significantly increased brainderived neurotrophic factor (BDNF) concentrations in serum and platelets of patients with asthma. ${ }^{10}$ This increase was abolished by the addition of the ICS fluticasone to the LABA treatment. The induction of BDNF by LABA and protection from this induction by ICSs were confirmed in vitro and, importantly, changes in BDNF concentrations in serum and platelets in the in vivo study correlated with deterioration in airway hyper-responsiveness (AHR) following LABA monotherapy, while, as previously reported many times, when ICSs were added to the LABA treatment there was a significant improvement in AHR. As there is increasing evidence that BDNF may enhance AHR and eosinophilia in allergic airway inflammation, ${ }^{11}$ these findings suggest that increased BDNF production may underlie some of the adverse effects of LABA monotherapy. They also suggest that concomitant ICS therapy may exert protective effects through inhibition of this induction.

These data have striking parallels with our own observations with another proinflammatory mediator implicated in asthma pathogenesis in a different experimental setting, and these two reports combined suggest a common molecular mechanism potentially to explain adverse effects of $\beta$-agonists in asthma. We studied the effects of $\beta$-agonists and ICSs on rhinovirus induction of interleukin-6 (IL-6) as IL-6 is a proinflammatory cytokine and as rhinovirus infections are the major cause of acute exacerbations of asthma. We observed that both salmeterol and the SABA salbutamol increased rhinovirus-induced IL-6 production; the induction of IL- 6 by salmeterol could also be induced directly by cAMP, and by other cAMP-elevating agents. ${ }^{12}$ Salmeterol increased rhinovirus-induced IL- 6 promoter activation via a mechanism dependent upon a cAMP response element (CRE) in the IL-6 promoter. Both SABAs and LABAs are well known to signal their beneficial effects via increasing intracellular levels of cAMP. These data indicate that potential adverse effects (eg, induction of IL-6) are mediated via exactly the same mechanism (induction of cAMP).

Interestingly, BDNF is also regulated via a CRE in its promoter. ${ }^{13}$ Although not studied directly by Lommatzsch and colleagues, these facts strongly suggest that the induction of BDNF by salmeterol is likely to have occurred via cAMPdependent induction of increased BDNF mRNA transcription via the CRE in the BDNF promoter. How many other molecules with potential adverse effects in asthma might also be induced by cAMP? The answer is not known, but a very recent report indicates that Th17 cells and IL-17 production are both directly induced by cAMP. ${ }^{14}$ Since Th17 cells and IL-17 have potent proinflammatory properties, ${ }^{15}$ it is likely that induction of these responses by cAMP-inducing agents in acute exacerbations of asthma would further increase airway inflammation. A number of other molecules implicated in asthma pathogenesis have also been shown to be regulated via a CRE in their promoter, including cyclo-oxygenase-2 (COX-2), ${ }^{16}$ matrix metalloprotease-2 (MMP-2 $)^{17}$ and the mucins MUC $^{18}$ and MUC5AC. ${ }^{19}$ These data suggest that $\beta$-agonists, while bronchodilating through smooth muscle relaxation, might at the same time have the potential to increase airway obstruction through increasing mucosal inflammation and oedema while simultaneously clogging the airway with secreted mucins.

A further important recent report suggests that the number of other genes that might be similarly regulated via CREs (and therefore potentially be induced by SABA or LABA treatment), might extend into hundreds and possibly thousands of genes as the cAMP response elementbinding protein (CREB) was found to occupy 4000 human gene promoter sites in vivo, including large numbers of transcription factors and other genes with potential proinflammatory activities. ${ }^{20}$ These studies were not performed in respiratory tissues/cells; however, the above data combined make it clear that SABAs and LABAs have the potential to induce many other genes in asthmatic lung tissue in addition to IL- 6 and BDNF.

In our in vitro studies, the ICS fluticasone alone inhibited rhinovirus induction of IL-6, and the addition of fluticasone to salmeterol at equimolar concentrations suppressed the induction of IL-6 observed with salmeterol, indicating that ICSs can counteract the induction of IL-6 observed with LABAs. Similar observations were made by Lommatzsch et al with respect to BDNF, as fluticasone was also shown to reduce $\mathrm{BDNF}$ concentrations when used alone in vitro, and, when combined with salmeterol, to block the induction of BDNF both in vitro and in vivo. ${ }^{10}$ Interestingly, each of IL-17, MMP-2, MUC8 and MUC5AC, reported to be induced by CAMP or via a CRE in their promoter in the studies cited above, ${ }^{14}$ 17-19 have independently also been shown to be suppressed by steroids. ${ }^{21-23}$ These data suggest that use of $\beta$-agonist/ICSs in 
combination inhalers may have other benefits beyond increasing compliance with ICS therapy and ensuring that ICS use is increased at times of worsening asthma control. The ICS component may also block direct genomic adverse effects of $\beta$-agonists while maintaining the beneficial bronchodilator effects, and synergistic or additive anti-inflammatory effects. $^{24} 25$ This suppression of direct adverse effects might be of particular importance at times of asthma exacerbation, when increased use of $\beta$-agonists is so common.

Further studies are urgently required to address which genes other than IL- 6 and BDNF are induced by SABAs and LABAs in human cells in vitro, to determine whether such genes are similarly induced by $\beta$-agonists in asthma in vivo, to investigate the doses at which beneficial effects (bronchodilatation) occur (likely to be low) and those at which adverse effects occur (likely to be higher), and to define the role of ICSs in counteracting these adverse effects.

Until such time as we have this further information, it would seem prudent to advise that LABA treatment should only be used in combination inhalers so that concomitant ICS treatment is obligatory. It is our view that prescribing LABAs and ICSs in separate inhalers is potentially unsafe as patients can (and many probably do) then take LABA monotherapy through failure to comply with the use of their separate ICS inhaler. It is likely that such practice would occur particularly at times of exacerbation, when desire for immediate symptom relief becomes a driving force guiding use of asthma treatments.

What should we do about SABA treatment? We currently have the paradox that LABA use as monotherapy is strongly discouraged by all treatment guidelines, including American Thoracic Society (ATS)/European Respiratory Society (ERS), British Thoracic Society (BTS) and Global Initiative for Asthma (GINA), while SABA monotherapy is recommended in mild asthma. Data continue to show (as they have done for many years) that mortality continues to occur in mild asthma in the context of excessive SABA usage without ICS cover $^{26}$ (and Shuaib Nasser personal communication). Given that there is clinical evidence of harm associated with $\beta$-agonist monotherapy, now with the added evidence of induction of potentially harmful mediators, as well as a molecular mechanism to explain both this induction and a protective effect of ICSs on this adverse effect, we believe that recommendations to combine a $\beta$-agonist/ICS in a single inhaler should now be extended to include SABA usage in the treatment of asthma. Combining the ICS with the SABA would ensure that ICS treatment is increased at times of increased disease activity, as well as potentially protecting against adverse effects of SABA overuse at the time of asthma exacerbation.

Acknowledgements: We are very grateful to Paul O'Byrne, Richard Beasley, Shuaib Nasser, Clive Page, Malcolm Sears, Ian Town and J Christian Virchow for their valuable comments on drafts of this manuscript.

Competing interests: SJ reports receiving speaker's fees, consulting fees and/or research grants from AstraZeneca, Centocor, GlaxoSmithKline, Pfizer, sanofi pasteur and Synairgen. He holds share options in Synairgen and is an author on patents for development of interferon therapy for exacerbations of airway disease. ME reports receiving research grants from GlaxoSmithKline.

Provenance and peer review: Commissioned; not externally peer reviewed.

Thorax 2009;64:739-741. doi:10.1136/thx.2009.119230

\section{REFERENCES}

1. Anderson HR, Ayres JG, Sturdy PM, et al. Bronchodilator treatment and deaths from asthma: case-control study. BMJ 2005;330:117.

2. Hasford J, Virchow JC. Excess mortality in patients with asthma on long-acting beta2-agonists. Eur Respir J 2006;28:900-2.

3. Crane J, Pearce N, Flatt A, et al. Prescribed fenotero and death from asthma in New Zealand, 1981-83 case-control study. Lancet 1989;1:917-22.

4. Beasley R, Nishima S, Pearce N, et al. Beta-agonist therapy and asthma mortality in Japan. Lancet 1998;351:1406-7.

5. Sears MR. Adverse effects of beta-agonists. J Allergy Clin Immunol 2002;110(6 Suppl):S322-8.

6. Mclvor RA, Pizzichini E, Turner MO, et al. Potential masking effects of salmeterol on airway inflammation in asthma. Am J Respir Crit Care Med 1998;158:924-30.

7. Nelson HS, Weiss ST, Bleecker ER, et al. The Salmeterol Multicenter Asthma Research Trial: a comparison of usual pharmacotherapy for asthma or usual pharmacotherapy plus salmeterol. Chest 2006;129:15-26

8. Drazen JM, Israel E, Boushey HA, et al. Comparison of regularly scheduled with as-needed use of albuterol in mild asthma. Asthma Clinical Research Network. N Engl J Med 1996;335:841-7.

9. Aldridge RE, Hancox RJ, Cowant JO, et al. Eosinophils and eosinophilic cationic protein in induced sputum and blood: effects of budesonide and terbutaline treatment. Ann Allergy Asthma Immunol 2002;89:492-7.

10. Lommatzsch $\mathbf{M}$, Lindner $Y$, Edner $A$, et al. Adverse effects of salmeterol in asthma: a neuronal perspective. Thorax 2009;64:763-9.
11. Nassenstein C, Braun A, Erpenbeck VJ, et al. The neurotrophins nerve growth factor, brain-derived neurotrophic factor, neurotrophin-3, and neurotrophin4 are survival and activation factors for eosinophils in patients with allergic bronchial asthma. J Exp Med 2003:198:455-67.

12. Edwards MR, Haas J, Panettieri RA Jr, et al. Corticosteroids and beta2 agonists differentially regulate rhinovirus-induced interleukin-6 via distinct cis-acting elements. J Biol Chem 2007;282:15366-75.

13. Tabuchi A, Sakaya H, Kisukeda T, et al Involvement of an upstream stimulatory factor as well as cAMP-responsive element-binding protein in the activation of brain-derived neurotrophic factor gene promoter I. J Biol Chem 2002;277:35920-31.

14. Boniface K, Bak-Jensen KS, Li Y, et al. Prostaglandin E2 regulates Th17 cell differentiation and function through cyclic AMP and EP2/EP4 receptor signaling. $J$ Exp Med 2009;206:535-48.

15. Kleinschek MA, Boniface K, Sadekova S, et al. Circulating and gut-resident human Th17 cells express CD161 and promote intestinal inflammation. J Exp Med 2009;206:525-34.

16. Wu W, Silbajoris RA, Cao D, et al. Regulation of cyclooxygenase-2 expression by cAMP response element and mRNA stability in a human airway epithelial cell line exposed to zinc. Toxicol Appl Pharmacol 2008;231:260-6.

17. Melnikova Vo, Mourad-Zeidan AA, Lev DC, et al. Platelet-activating factor mediates MMP-2 expression and activation via phosphorylation of cAMP-response element-binding protein and contributes to melanoma metastasis. J Biol Chem 2006;281:2911-22.

18. Song KS, Seong JK, Chung KC, et al. Induction of MUC8 gene expression by interleukin- 1 beta is mediated by a sequential ERK MAPK/RSK1/CREB cascade pathway in human airway epithelial cells. J Biol Chem 2003;278:34890-6.

19. Song KS, Lee TJ, Kim K, et al. cAMP-responding element-binding protein and c-Ets1 interact in the regulation of ATP-dependent MUC5AC gene expression. J Biol Chem 2008;283:26869-78.

20. Zhang X, Odom DT, Koo SH, et al. Genome-wide analysis of cAMP-response element binding protein occupancy, phosphorylation, and target gene activation in human tissues. Proc Natl Acad Sci USA 2005;102:4459-64.

21. Chen Y, Nickola TJ, DiFronzo NL, et al. Dexamethasone-mediated repression of MUC5AC gene expression in human lung epithelial cells. Am J Respir Cell Mol Biol 2006;34:338-47.

22. Ishinaga H, Takeuchi K, Kishioka $C$, et al. Effects of dexamethasone on mucin gene expression in cultured human nasal epithelial cells. Laryngoscope 2002;112:1436-40.

23. Molet SM, Hamid QA, Hamilos DL. IL-11 and IL-17 expression in nasal polyps: relationship to collagen deposition and suppression by intranasal fluticasone propionate. Laryngoscope 2003;113:1803-12.

24. Edwards MR, Johnson MW, Johnston SL. Combination therapy: synergistic suppression of virus induced chemokines in airway epithelial cells. Am J Respir Cell Mol Biol 2006;34:616-24.

25. Kaur M, Holden NS, Wilson SM, et al. Effect of beta2-adrenoceptor agonists and other cAMPelevating agents on inflammatory gene expression in human ASM cells: a role for protein kinase A. Am J Physiol Lung Cell Mol Physiol 2008;295:L505-14.

26. Harrison B, Stephenson P, Mohan G, et al. An ongoing Confidential Enquiry into asthma deaths in the Eastern Region of the UK, 2001-2003. Prim Care Respir J 2005;14:303-13. 